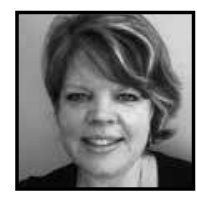

\title{
Portraits of Home: Working in Community Daycare Homes in New Brunswick
}

\author{
Tara-Lynn Scheffel, Nipissing University
}

\begin{abstract}
Part of a larger project involving the design and implementation of a first-time curriculum framework for early childhood care and learning in New Brunswick, this paper highlights the stories of Canadian early childhood educators working in home-based daycares. In particular, a common theme of "sense of place" is discussed in relation to four portraits that are presented in this article: (1) Home as Survival, (2) Transition to Home, (3) Home as Transition, and (4) Coming Home. Through each portrait, the role of life changes and transitioning towards new beginnings is discussed, along with possibilities and constraints for ongoing discussion and reflection.
\end{abstract}

\section{Introduction}

Throughout Canada and the world there is a growing recognition of the need to value and support the learning and child care of our youngest children. (NBCF, 2008, p. 3)

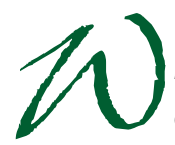

ith this purpose in mind, the New Brunswick Curriculum Framework for Early Learning and Child Care - English (NBCF) sought to design "an emergent and engaging curriculum for children from birth to five, one that [would] encourage optimum development in an atmosphere of trust, security and respect" (p. 3). While the design and implementation of the curriculum framework has been explored elsewhere (Nason \& Whitty, 2007; Whitty, 2009; Rose \& Whitty, 2010), the goal of this article is to highlight the stories of four Canadian early childhood educators working in home-based daycares. From its onset, the NBCF recognized the distinctness of homebased settings and aimed to create a framework that was "suited for home-based and centre-based care" (NBCF, 2008, p. 3). Moreover, the implementation of the framework 
aimed to provide spaces for early years practitioners "to raise critical questions from the vantage of their experiences" (Nason \& Whitty, 2007, p. 277). With this in mind, my role in working with home-based educators began with the design of a professional institute geared specifically to this group of educators as they faced the implementation of this first-ever curriculum framework. It grew in response to educators' desires to seek out spaces for building collegial conversations as they explored what made them similar and unique to centre-based settings, and also raised questions of professionalism, legitimacy and the need for networking.

At the time of the study, there were 32 identified Community Home Day Cares in the province. According to the New Brunswick Department of Education and Early Childhood Development (2013), Community Day Care Homes, also known as Family Day Care Homes are approved childcare services located within an individual's home with a smaller number of children. Specifically, providers may provide services to:

- Three Infants (up to age 24 months), or

- Five children of the ages two to five, or

- Nine children who are of the ages six and over, or

- Six children where the children are of the ages five and under and six and over, including those of the operator.

(http://www1.gnb.ca/0000/CommunityDayCare/index-e.asp?District_Name=DSF-NE)

For the purposes of this article, I will use the term home-based to encompass both this term and other similarly intended terms in the research literature.

A total of 21 home-based educators attended the institute with the addition of six others who identified themselves as similar to home educators (i.e., due to small or home-like spaces). As a Curriculum On-Site Support Facilitator, I was also assigned to work specifically with home-based educators as they implemented the new curriculum framework. This included on-site visits ( $3 \times 2$ hours), ongoing email/phone communication, and the collection of artifacts for developing curricular support documents. In particular, the goal was to create a support pamphlet specific to Community Day Care Homes (see Scheffel, 2010). It was here that the stories of four educators began to stand out. Wanting to hear more about their views as home-based educators, I invited them to participate in a focus group interview. The portraits that follow share the stories of these four educators that I came to know and work with throughout the project. First, however, while there is not a large amount of research looking at home-based daycares, it is here I turn next to set the context for what makes home-based daycares unique and worthy of this closer look. 


\section{What Makes Home-Based Daycares Unique?}

Using the analogy of looking through "A Window into Home-Based Pedagogy," Wright (2004) offered the following comparison to centre-based care:

- multiple sites vs. one centrally located site;

- "personal" flavor of the educator's home vs. "public" flavor of a site designated for early childhood education;

- omnipresence of a single educator vs. multiple educators;

- everyday occurrences and contextually relevant tools vs. planned activity-based experiences. (p. 10)

Contextually relevant tools refer to those tools that uniquely make up the context of a home, such as baking for the arrival of a neighbor, watering plants in the garden, or walking to the mailbox.

Wright (2005) built on this comparison with eight insights for enriching understandings of learning environments within home-based early childhood settings. These insights supported her earlier comparison, suggesting that catalysts for learning occur from the movement between home and community, as well as the contextually relevant tools within home contexts. Interpersonal relationships were also found to characterize these home-based settings with strong connections forming between the children's and educator's families. In addition, the educator's role was viewed as critical to the learning environment. Time was also seen to be "both a constraining and enabling feature of these environments" (p. 43). For example, smaller numbers of children allowed for greater time with educators and sustained lengths of time for children's explorations. However, a visitor might interrupt or postpone a planned activity. Finally, the richness of home-based settings was considered valuable for both older and younger children.

Freeman and Vakil (2007) further acknowledged the uniqueness of home-based settings with four similar characteristics, including: small enrollments, a strong acquaintance with families that offers continuity in terms of home-school connections, and the use of multi-age groupings. Presenting four case studies, Freeman and Vakil (2007) discovered, "In the stories of Rose, Iris, Daisy, and Violet, their 'teaching' is not a delivery of curriculum to the child as it is a discovery with a more capable other" (p. 275). Drawing on the narratives of these educators, they shared five essential themes of learning. The first related to children's skills for learning and includes: learning through 
observation, learning to resolve problems, and learning by investigation. The second theme involved essential opportunities, including: both child-negotiated, open-ended opportunities, such as a child wanting to add marshmallows when making muffins, as well as opportunities for hands-on learning. The third theme revolved around play, considering games and pretense involved when children engage in dramatic play. Social-emotional learning made up the fourth theme, while the fifth included that of meaningful learning, such as a visit by an elderly neighbor that became an opportunity for intergenerational learning. Reflection upon these themes and narratives was integrated into the professional institute, offering a starting point for discussions with home-based educators as they considered similar stories, opportunities for change and connections to curriculum goals.

At the same time, we considered Carter's (2005) suggestion that there are many lessons to be learned from family home providers. These lessons are referred to as strategies, emphasizing that they are purposeful rather than incidental. For example, displaying pictures to create a family-like environment creates a focus on home, suggesting an extension of family. Other strategies include forming neighborhood networks and collaborating on professional activities in order to emphasize the building of networks and collegial relationships. The last set of strategies focuses on developing awareness and policies, as well as advocating to create time for professional development.

From these discussions, key successes shared during the institute included being part of an extended family, freedom in planning/structure, and the ability to work from home. The most predominant concern revolved around feelings of isolation as educators shared their appreciation for having an institute focused solely upon their contexts. Like Carter (2005), it seemed that they, too, had experienced how "the different components of [their] field often stay[ed] in [their] own niches...we miss opportunities to cross-pollinate" (p. 71). Perhaps this is why at the conclusion of the institute, 24 participants expressed interest in joining an online discussion group as an opportunity for networking. While not the focus of this article, the discussion board reinforced a desire for ongoing conversation amongst these home-based educators, setting the stage for the portraits to be shared.

Recognizing the uniqueness of home-based settings, this paper builds on the research presented above to present a narrative case study of four educators with the goal of sharing insights within a Canadian context. The focus is on the educators themselves and their understandings of the work they do. While curricular discussions are inherent, what stood out most was a common theme of "sense of place" as contributing to sense of belonging when seeking out home as a workplace. This sense of place 
took on four roles: (1) Home as Survival, (2) Transition to Home, (3) Home as Transition, and (4) Coming Home. Through each portrait, the role of life changes and transitioning towards new beginnings is evident.

\section{Portraits of Home Educators}

As I began to talk with the four educators about their work, it became apparent that all had chosen to open home-based daycares for different reasons and life circumstances. In particular, the role of life changes leading towards new beginnings rang true for each. For Margie (all names are pseudonyms), it was a divorce and the need to support her own children. Pat, on the other hand, wanted to spend more time with her son and found this was something that her previous job did not allow. Alternatively, Vanessa saw her home daycare as a stepping-stone to opening a larger daycare in the future. Megan, however, had worked for years as the director of a larger daycare and found herself seeking a smaller, home-based space for the children she worked with. It is their stories that I turn to next.

\section{Margie: Home as Survival}

"...My own experience was really all that I had to fall back on ..."

Margie had been caring for children in her home for six years when in 2000, she received a letter in the mail inquiring as to whether or not she was using her home for a daycare. To Margie, it felt like "a slap in the face." It was a divorce and the need to support her own children that began her career as a home daycare provider, but it would be this letter that prompted her to become licensed.

Upon reflection, Margie shared: "The change was great... but it was really scary when you open up that letter and you think, $\mathrm{OH}$ ! I don't have a job!" Personally, she struggled with the negative perception of care that the letter suggested, while professionally, she found herself setting new-and perhaps much needed-guidelines and regulations for a parent handbook.

With this change, Margie now named herself as a childcare provider instead of a babysitter. She hesitated to use the word teacher. "Not teacher. I don't use that word. I'm fine with provider because I don't have my ECE...so 'educator' doesn't seem to fit either." Despite this, she still felt a certain stigma associated with her work. When her husband introduced her work the reaction she often received was one of, "Ok, when is she going to get a real job?" 
The children in Margie's care have always been of mixed age groupings, from infant to age 5 . In terms of materials, Margie believed a sense of home was what parents were looking for, not expecting to have all the big items that a centre might have. This same understanding led her to treat the children in her care with the same respect they would receive in their own homes. Though she sometimes felt limited because she did not provide transportation, she found that parents often had a look of relief on their faces when she shared this with them. "They chose a community home daycare for a reason," she explained. "It's because they wish they could be home and they can't. So this is the next best thing."

One of the outdoor spaces she loved best as a home provider was her garden. The children, along with her husband's help, had created a "Garden of Wonders." Reflecting on the project, Margie found, "It was evident right away which children had been exposed to some type of gardening...I didn't bring out the little shovels for this very reason...so they would all experience the feeling of the soil in their hands."

The amount of extra time for documentation was one of Margie's biggest concerns and should the expectations become too great, it was the one thing that made her consider not running a home-based daycare anymore. "We only have so much wall space," she added. To help with this, she had decided to keep all of her inquiry-based planning webs in a binder to show her regional coordinator what they had read, learned, and explored.

"There is no escape," Margie said, especially when you work in the space where you live. But, "I love what I do." She recalled memorable moments of parents giving her credit in teaching their children, and of children accidentally calling her mom, knowing that they felt comfortable, valued, and safe with her.

\section{Themes/Tensions Arising}

Within Margie's story are several underlying themes. The first is the tension between public and private spaces. As a home educator, she shared her home space with her daycare and so tensions arose when it came to creating a space that fit both purposes. For example, Margie shared that while she appreciated the work that inspectors do, she wished there was greater understanding that home educators work independently and do not have someone to cover them at a moment's notice for a meeting. If a need arises with a child, the child must come first. 
Inherent within this tension is another, that of personal and professional expectations. This arose in particular because of the curriculum implementation and the new perceived expectations being placed upon Margie, such as with the questions surrounding documentation and valued materials. Margie admitted to losing some of her enthusiasm as the new curriculum framework was introduced. Once the initial experience was over, however, her enthusiasm re-appeared. I suspect this was in part due to needing time to see how the new professional expectations fit within her personal expectations for care and learning. She was coming to understand, as Lewin-Benham (2011) discussed, that documentation is "an intentional collection" and a way of "recording and preserving evidence of children's activities and passions" (p. 141). Margie was very conscientious and so wanted to do what was expected of her. Yet, there were many unknowns in terms of how the curriculum would affect her personally as a home educator, such as cluttered wall space. Just as Lewin-Benham (2011) reminds us that documentation "releases walls from the burden of displaying commercial materials" (p. 141), Margie needed to find a way to display documentation that recognized the walls as her home. The use of a binder offered a negotiated tool for moving towards change.

Closely linked to the above tensions are the valuing of her home as a space for learning and herself as a childcare provider rather than a babysitter. As Margie shared, her experience was that of raising her own children. When it came to being licensed and creating documents such as a parent handbook, it was her "own experience" that she "had to fall back on..." And Margie did have expertise and knowledge to share. She became a mentor to Pat, who we will meet next.

\section{Pat: Transition to Home}

"I never saw my 2-year-old son... it was terrible..."

Pat started her home daycare six years prior to this study because she needed a life change. For 20 years she had worked in the hotel industry but found herself questioning why she was working 24-7, never seeing her 2-year-old son. "It was terrible," she reflected. Having gotten to know Margie, the provider at her son's daycare, Pat began to ask advice about starting her own daycare. Initially she took in three children in addition to her son, "just to see if it was going to work." She did not want to go through the process if she discovered it was not what she wanted to do. At the same time, she knew that once she made the decision to go ahead, it was going to be her business and she wanted it to be professional. 
When it came to how she defined herself, however, Pat was hesitant to use words like educator or provider, instead placing the emphasis on the context: "I just say I have a daycare, I don't really....know." She also considered herself a "second mom."

As part of a quality standards group in her region, Pat volunteered to take on a leadership role in welcoming new home-based educators and helping them to navigate through the standards. She was also very vocal about wanting others to understand the experience of home-based educators, wishing at times that inspectors took the needs of their unique contexts into consideration more often. Flexibility was key, she believed. As a businesswoman she understood the need for standards and spot checks, and believed this was important. However, finding the time to engage in professional dialogue with inspectors about these standards presented challenges when, as the sole educator in her space, she was also caring for children during these visits. "How can I concentrate on what they want me to do," she questioned, "when I'm trying to look after [a] crying child?"

Pat was not convinced that the new curriculum framework had changed her practice in significant ways, believing it was very similar to what she was already doing. Like Margie, she felt the pressure of added time and expense for documentation and wondered how to show proof of what she had done without holding on to copies of everything. She had visited some larger sites, but found herself thinking, "I could not work with five hundred things on my wall everyday. It would give me a headache." "It's my home," she added." Despite her reservations, however, she noticed that the children did look to the documentation to revisit learning.

Remembering what it was like to be a parent with children in daycare, Pat found it difficult to ask her parents to do anything outside of the daycare, such as trips to Green Village, a local flower nursery, in particular as she did not take on this driving role herself. She also found it a struggle to bring community members into her space with her small enrollment. Recently she found herself pleading with a local bird expert to come and talk with the children as part of a bird project. A few years ago, she was able to convince the Fire Department to come for a visit, but had been unable to convince them since, due to her lower numbers as a home-based daycare.

Describing her context, Pat explained, "We're small and we're homey and we have such personal relationships with our parents." Recalling a mother crediting her for how well her son was doing, she reflected, "That's amazing to me because I don't have training. That was all just common sense," Pat reflected. 


\section{Themes/Tensions Arising}

There is a recurring theme of professionalism in Pat's story-from credibility in advertising when recruiting new parents to joining the quality standards group. When it came to attending curriculum institutes with other early childhood educators, this was something that stood out to her as lacking in the field. Referring to both level of respect and even clothing, she stressed, "I have a lot of pride in my work. I built this business..." It is perhaps this same sense of pride about her work that left her feeling disconcerted when consistently struggling to bring community members into her space with her small enrollment. She was looking to her local community to value what she did but unlike Megan, whose story we will hear shortly, these opportunities did not always come easily.

Both Margie and Pat seemed to feel the pressure of accountability, though Pat was most vocal about this in our discussions. Questions such as how to prove the learning that took place and what to expect of inspectors and coordinators conveyed the pressure associated with demonstrating credibility within the profession. That this was a concern for Pat and Margie is perhaps not surprising given they do not have an ECE background and are drawing on other strengths and experiences, such as being a parent and running a business. These ongoing questions also speak to the newness of concepts within the curriculum framework, such as inquiry-based learning and not having a pre-set plan every day. As Whitty (2009) shares:

Emergent curriculum (how the field has named the curriculum), which is defined as working from children's and educators' interests within a meaning-making paradigm (Dahlberg, Moss, \& Pence, 2007; Wien, 2008), was largely an unfamiliar concept with the field; typically children and educators were guided through the day by the clock and through the year by the weekly themes. (p. 46)

They were each left in a space of having to reconsider what they did as home-based educators, which momentarily took away the love they had for their work until they were able to ask questions, have someone visit them on-site, and recognize the flexibility within the curriculum framework that did not dictate they all be the same.

\section{Vanessa-Home as Transition}

"My goal is to keep growing...Eventually we'd like to buy another building..."

Prior to opening her home-based daycare, Vanessa had worked in the early childhood field for eight years. Initially pursuing a teaching degree out of province, she became 
pregnant and opted to remain closer to home with the support of her family. Not long after, she completed her early childhood education. Interviewing at various daycares, she was disappointed to hear directive type comments such as, "This is what we do and this is how we do it." "What if I have an awesome idea?" she asked one of her interviewers. Feeling dismissed, Vanessa knew in that moment that this was not what she wanted. She needed "the freedom to grow professionally."

With the buying of her own home, she found the "the perfect opportunity" to open her own daycare. She researched and prepared all the necessary items for licensing, explaining: "I wanted to be taken seriously as a professional... if you're any bit educated in the field, you don't want to be called a babysitter." Aware of government grants for having infants and extended hours, Vanessa also took advantage of opportunities for additional funding.

Though a friend had warned her at the time about an upcoming curriculum framework for the province, she found herself excited to see the binder, secretly thinking, "That looks awesome." At the beginning, however, she admitted, "I was worried that I wasn't doing it right or there was a set way to incorporate emergent curriculum but there really isn't...it's what your group needs and [who] you are."

Though much of the framework was familiar to her from her coursework, she felt she "learned a lot more just to play...I've always done it but this has taught me how to just be in the moment with the kids." For Vanessa, it was also "encouraging to know that the government [was] taking more interest in educators." Her hope was that the field would become more professional, since she believed many were used to it not being this way.

The environment Vanessa aimed to create was "cozy," "family-oriented," and "childcentered." In terms of the layout and access to resources, Vanessa made "a big effort to put everything at their level." She also often changed the layout with input from the children. In addition, the children and parents were part of her extended family. Vanessa's father, known as "Grampy" to all the children, was also a frequent visitor, as well as her husband, who at the time was recovering from knee surgery. His injury instigated much play around doctors and providing care, with the children role-playing alongside him.

The park up the street served as a key outdoor space for walks and playful adventures. The children made pretend campfires under the picnic tables and flew to faraway lands on the swings. Vanessa also drove the children to various outside locations such as the local library and the fish store as part of their ongoing inquiries. 
With regards to documentation, Vanessa agreed it could get overwhelming and reminded herself to set goals such as, "I am going to write one learning story for each child this month." She was encouraged by the children's excitement and their anticipation of new stories and pictures.

While Vanessa recognized that many of her home-based colleagues saw themselves as different from larger daycares, she saw them as more alike than different. As such, she felt both a need to get together with other home educators, but also to be included with the professional development that is required for all educators, regardless of context.

\section{Themes/Tensions Arising}

Vanessa thrived on learning, both for herself and the children. In addition to the professional development hours that were part of the curriculum implementation, she was taking additional qualification courses for her ECE. When I visited her site, she often shared new ideas she had implemented that drew on concepts and theories she was learning about in her coursework and identifying in the curriculum framework. One particular success involved holding an art show with the children as a way of both valuing their work and encouraging parents to come into the space. The online discussion board became a place for Vanessa to share this ongoing learning: "I just wrapped up a professional development course on Art and Creativity and I learned so much! It really reminded me that children's art is more about the process to the kids - the act of MAKING it, not the end product or result!"

Despite this venue for conversation, Vanessa expressed she had greater hopes for receiving more feedback from her colleagues about what she was doing: "I was so excited about my daycare's art show and not one person posted any reply or comment to my post on Monday. I am trying to be positive and keep it going but feeling frustrated I MUST say..."

For Vanessa, the online forum could not replace that personal, immediate feedback for which she had hoped, leading to feelings of frustration and isolation.

When it came to learning stories, Vanessa saw the value in this assessment practice, but also recognized the time needed to learn how to "understand children's thinking and their processes rather than just end products" (Hatherly \& Sands, 2002, p. 3). Setting a goal of one per month, she was attempting to find her way through the "balancing act" described by Carr and Lee (2012), also recognizing the "learning curve in 
using in-process documentation" from a learner perspective (Phillips \& Swanson, 2006). Yet, despite this need for balance, Vanessa recognized learning stories as "relevant to all care settings, including Family Day Care" (Centre for Community Child Health, 2007, p. 3), as she worked towards the larger curriculum goals of sharing insights into children's strengths and interests.

Despite this recognition, Vanessa often felt as if she did not quite fit with the other home daycares, not in the sense of being part of their community, but feeling like she did things very different from them. Her youth and eagerness for new ideas, as well as her artistic bent, signified her uniqueness as an educator. Until she met up with Margie, Pat, and Megan, she had been struggling with the dichotomy of home daycare vs. professional daycare. She wanted to run her home-based daycare as a professional business but was unsure that others felt similarly. Like Pat, she took pride in what she did and wanted to be seen as a professional. Regardless of context, she desired for all early childhood educators to feel this same passion and pride.

\section{Megan: Coming Home}

"I have learned since I came home to work that the more relaxed I am, the more free I am. The more I give to the children and myself, the more learning that takes place."

An educator and director, Megan worked in early childhood centres for 27+ years before beginning her own home-based childcare in 2005. Looking back, she thinks she was "cut out to probably be a teacher," but life experiences led her in a different direction and for her, working in early childhood education was a close alternative.

Unsure at first if she would become licensed, her regional coordinator asked her why she would go to all this work of providing a service within the standards and not license. Upon reflection, Megan realized it was freedom she was seeking, to be on her own and provide for children the way she had wanted to for years. She explained: "...when you work for someone else you have certain limitations as to what you can and can't do and sometime philosophies aren't the same..."

Her coordinator assured her that licensing did not mean she had to give up what she felt was best and so she became licensed.

Megan aimed to create a welcoming environment. "I want them to feel that when they come here, this is their home," she explained. "I want them to feel free and so welcomed." It is not a "running wild" or "boundary-less" freedom, she elaborated, but, 
"...an environment where they would have one individual to oversee their day in their parent's absence, and this person would want to give them.... a home away from home."

For this reason, Megan believed "the environment needs to be filled with their things." An avid photographer, Megan framed pictures of the children within her space as a way of documenting the learning that was taking place. In addition, she invited the children to join her in the process.

The outdoor environment also played a keen role in Megan's programming-from walks to the nearby riverbed in the summer to campfires and roasting marshmallows around a fire pit in the winter. The beauty of nature had a special place for both her and the children as they collected artifacts of their journeys (shells, rocks, pinecones, beach glass...) to be used for art making or held in special containers upon their return.

Megan noted that one of the biggest struggles as a home educator is having "no breaks in what you do." Balance was something she aimed for constantly in order to give time to both the children and herself. For this reason, she recommended looking to the community "to see what you can create for yourself," whether it is a neighbour who has wood to share or someone to read to the children. One senior neighbour in particular had become a prominent figure in the lives of the children in Megan's program. From Christmas baking to decorating the neighbour's cast when she broke her leg, the children had come to know and enjoy spending time with this special community friend.

At this point in her career, Megan selected her clients as much as they selected her, noting that it was learning about what will make a good fit. She wanted families to know they can call her if they are ever in need, "every bit as much as family." For Megan, this personal connection with families was one of the differences between larger centres and community home daycare, something she longed for in her previous experiences.

\section{Themes/Tensions Arising}

Starting her own home-based centre marked a sense of "coming home" to Megan, both physically and pedagogically in the new-found sense of freedom she felt as an educator. As a director, she had often felt constrained to gain board approval for ideas and create an environment that encompassed freedom to explore. Through her homebased learning environment, Megan could now share rather than defend her beliefs. In doing so, Megan recognized that, "in the early years, the environment is the curriculum" 
(Lewin-Benham, 2011, p. 67). Relationships were also key to this understanding as Megan sought to create a family-like learning space for the children within her care. Similar to the goals of Reggio educators, Megan understood that "aesthetics means not only how something looks and functions but its potential to shape experience, and in doing so, to shape the mind" (p. 79). Megan's framed artwork, neighbourhood networking, and the blending of indoor-outdoor learning spaces all contributed to the uniqueness of her learning space and the lessons suggested by Carter (2005) as fitting of all early learning contexts.

Moreover, the idea of networking was central to Megan's story. For example, Megan took full advantage of her previous director role to speak with other directors and to attend local professional development opportunities that were initiated in her region prior to the province-wide curriculum implementation. In fact, Megan's name was often recommended to new home-based educators as someone from whom to seek advice and ask questions. With the new curriculum framework, Megan believed they were at the beginning of "something so special" for home educators in the province. Her advocacy, another one of Carter's (2005) lessons to be learned from home-based educators, resonated with her colleagues as they considered the unique programs and spaces they offered. Together, they began to share their voices from "the vantage of their experiences" (Nason \& Whitty, 2007, p. 277), recognizing the ways they might do things differently from larger centres but with the same overarching goals in mind.

Despite her years of experience, Megan, too, struggled with feelings of isolation as a home-based educator. The reality of no breaks during the workday was intricately tied to a need to balance time for the children and herself. Creating community was one way that Megan aimed to achieve this balance, whether with the involvement of parents, trusted neighbours, ECE students, or co-workers. Unlike the others, she was financially able to hire someone to help offset her time for administrative details such as writing learning stories. Megan recognized the pay cut involved and that "hiring an employee in this size of a daycare" was likely unheard of. But it was important to her to find balance within her home context while still providing a home-space that was inviting and rich in learning experiences. 


\section{Conclusion}

As with the research shared earlier, similar themes of interpersonal relationships, connections with families and community, and uniqueness of setting and learning opportunities stand out in these four educators' stories (Wright, 2005; Freeman \& Vakil, 2007; Carter, 2005). Furthermore, while each became licensed for a different reason, they all found that licensing was an important step forward in legitimizing what they did. Similar to Lanigan's (2011) findings, they valued professionalism and believed that they offered "a unique segment of the early learning and care system worthy of district professional development and respect" (p. 399). For some, like Margie, this was a newfound understanding in terms of seeing herself as an educator. For others, like Vanessa, this sense of professionalism legitimized her early childhood education. Regardless, all echoed a similar desire for inspectors, as well as those involved in supporting the implementation of the curriculum framework, to recognize the uniqueness of their spaces that also served as their homes. Above all, despite the successes and struggles that were a part of each of their journeys, each educator viewed the importance of networking as key to being a home-based educator. Lanigan (2011) found that when providing professional development for home-based educators, of critical importance is the need for trust and the non-judgmental collaborative opportunities. The stories shared here reinforce this need for professional learning opportunities, recognizing the need for time and space to get to know one another, to give and receive feedback, and to place oneself in the role of learner.

In her ongoing leadership role, Megan has kept in touch with me, sharing goals on behalf of home-based educators to continue to find ways to network with one another. Ongoing constraints include distance (with educators spread across the province), time (especially as the sole educator in their spaces), and difficulty in securing online venues like the one used through UNB due to issues of access and confidentiality. Yet, their goal for networking persists and speaks to the very need for their stories to be shared. For, as Jalongo and Isenberg (1995) convey, "Story is an indispensable part of the educational dialogue. It encourages teachers to talk, to exchange beliefs, to share experiences with colleagues, and to wrestle with the dilemmas associated with teaching" (p. 152). As more than babysitters, home-based educators share a similar need for educational dialogue to further the work they do. Through this dialogue, tensions and successes may resonate, but more importantly there is the opportunity to make insightful observations of one's practice, becoming "professionally aware" of the work they do (p. 153). In light of changes, such as a new curricular framework requiring home-based educators to take on new understandings of emergent curriculum and documentation, central 
questions revolved around professionalism, legitimacy, and networking. Through their collaborations, these four educators sought mentorship from one another as they also began to take on mentorship roles within a growing community of practice (Wenger, 1998), a goal also set forth by Nason and Whitty (2007).

Looking ahead, many possibilities remain that might be supported by local and provincial governments or considered as areas for future research. These include:

- Continuing to forge a place for home educators to be recognized, appreciated and valued for the work they do;

- Creating spaces for dialogue, learning and mentorship;

- Sharing of ongoing stories to create conversations and sense of belonging.

As I conclude, I am reminded of Freeman and Vakil's (2007) phrasing about the power of story to convey understandings and prompt reflections about the work of educators in home-based settings. As we continue forward in our considerations of ways to support home-based educators, let us consider: In the stories of Margie, Pat, Vanessa, and Megan, each has travelled a different path but seeks a similar valuing of the work they do as home educators, along with a need to connect, share, and learn alongside others as they continue their journey.

\section{References}

Carr, M., \& Lee, W. (2012). Learning stories: Constructing learner identities in early education. Thousand Oaks, CA: Sage Publications.

Carter, M. (January/February 2005). Lessons from family home providers. Child Care Information Exchange, 71-74.

Centre for Community Child Health. (2007). Learning stories. Childcare \& Children's Health, 10(4), 1-4.

Dahlberg, G., Moss, P., \& Pence, A. (2007). Beyond quality in early childhood education and care: Languages of evaluation (2nd ed.). London: Falmer Press.

Department of Education and Early Childhood Development. (2013). List of approved community day care homes. Retrieved from http://www1.gnb.ca/0000/Community DayCare/index-e.asp
Freeman, R. G., \& Vakil, S. (2007). The pedagogical experiences and practices of family child care providers. Early Childhood Education Journal, 35(3), 269-276.

Hatherly, A., \& Sands, L. (2002). So what is different about learning stories? First years: Nga Tau Tuatahi. New Zealand Journal of Infant and Toddler Education, 4(1), 8-12.

Jalongo, M. R., \& Isenberg, J. P. (1995). Teachers' stories: from personal narrative to professional insight. San Francisco: Jossey-Bass Inc.

Lanigan, J. (March 2011). Family Child Care Providers' Perspectives Regarding Effective Professional Development and Their Role in the Child Care System: A Qualitative Study. Early Childhood Education Journal, 38(6), 399-409. 
Lewin-Benham, A. (2011). Twelve best practices for early childhood education: Integrating Reggio and other inspired approaches. New York: Teachers College Press.

Nason, P., \& Whitty, P. (2007). Bringing action research to the curriculum development process. Educational Action Research, 15(2), 271-281.

Phillips, L., \& Swanson, S. (2006). Learning to document children's learning: Looking at the process with early childhood education students. Canadian Children, 31(2), 26-31.

Rose, S., \& Whitty, P. (2010). "Where do we find the time to do this?" Struggling against the tyranny of time. The Alberta Journal of Educational Research, 56(3), 257-273.

Scheffel, T-L (2010). Community Day Care Homes. A Professional Curriculum Pamphlet for the New Brunswick Curriculum Framework for Early Learning and Child Care (English). http://www.gnb.ca/0000/ECHDPE/pdf/ CommHomeDayCares_e.pdf

University of New Brunswick Early Childhood Research and Development Team. (2008). New Brunswick Curriculum Framework for Early Learning and Child Care (English). Fredericton: Department in Social Development.
Wenger, E. (1998). Communities of practice: learning, meaning and identity. Cambridge: Cambridge University Press.

Whitty, P. (2009). Towards designing a postfoundational curriculum document. In L. lannacci and P. Whitty (Eds.), Early Childhood Curricula: Reconceptualist Perspectives (pp. 35-62). Detselig Press.

Wien, C. A. (2008, October). Emergent curriculum - What on earth do they mean by that? Keynote address presented at Learning for Three, Four, and Five Year Olds, New Brunswick Curriculum Framework Institute, Fredericton, NB.

Wright, L. (2004). Spotlight on family day care: A window into home-based pedagogy. Early Childhood Folio, 8, 9-13.

Wright, L. (2005). Early childhood curriculum in family day care: People, places and things. Occasional Paper Series No.17, Institute for Early Childhood Studies, Victoria University of Wellington, New Zealand.

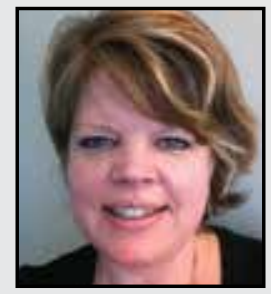

Tara-Lynn Scheffel is an Assistant Professor in the Schulich School of Education at Nipissing University, where she teaches courses in both the pre-service and graduate programs in Language Arts and Literacy. Previously an elementary school teacher, her research interests are primarily literacy-related with a focus on literacy engagement, as well as research with young children and opportunities for reflective practice and the sharing of practitioner stories. Early childhood care and learning, including community-based literacy initiatives, are also central to her ongoing work. She currently serves as the President of the Language and Literacy Researchers of Canada. 